\title{
Development of the Special Tools for On-load Tap-changer Suspended Core
}

\author{
Zhu Yuanda ${ }^{1, a}$, Zhang Su ${ }^{1, a}$, Tang Qishu ${ }^{2, b}$, Shan Jia ${ }^{3, c}$, Zhang Zhen ${ }^{1, a}$ \\ ${ }^{1}$ Liaoning Skill Training Center \\ ${ }^{2}$ Benxi Power Supply Company, State Grid Liaoning Electric Power Supply Co., Ltd. \\ ${ }^{3}$ Fushun Power Supply Company, State Grid Liaoning Electric Power Supply Co., Ltd. \\ a 22181221@qq.com, ${ }^{\text {b }}$ bxwl_650928@126.com, ${ }^{\text {c } 105442377 @ q q . c o m ~}$
}

Keywords: transformer; on-load tap changer

\begin{abstract}
In today's transmission and distribution system, large transformers are widely equipped with on-load tap changer (hereinafter referred to as OLTC) to ensure the voltage quality of the system and users. Due to the complex mechanical structure and high operation frequency, there are often abnormal situations during the operating and functioning process. This paper focuses on a tool for OLTC maintenance equipment, especially for OLTC core barrel removal.
\end{abstract}

\section{Introduction}

On-load tap changer is a switching device providing constant voltage when load on the transformer changes. For the installation, core barrel of OLTC penetrates through the central hole upwards and then is fixed to the jacket by a bolt; frequent actions in that OLTC requires constant action and the load current should be cut off during work and other reasons in manufacturing process, installation and functioning conditions of OLTC result in high fault rate and OLTC needs to be disassembled and repaired. Currently, core barrel is disassembled by opening the bolt connecting the core barrel and jacket and then released down and separated with the jacket by crane hooking the core barrel. This disassembling method demands more operators; in addition, there are also other problems: the complex substation environment, small open space and large number of equipment; especially indoor transformer and crane demolition is inconvenient; strength of the crane is hard to control and can easily damage the OLTC and bring safety hazard to operators. In order to solve the above problems, this paper proposes a core barrel removal tool for OLTC that can reduces the number of operators, is easy to disassemble, reduces the occurrence of OLTC damages and increases the operating safety of disassembles.

\section{On-load Tap Changer}

On-load tap changer is a switching device providing constant voltage when load on the transformer changes. The basic principle is to achieve the switching of transformer windings equatorial joint under the condition of uninterrupted load current, thus change the number of windings turns, i.e. voltage ratio of the transformer, and ultimately realize the purpose of regulating voltage

In today's transmission and distribution system, large transformers are widely equipped with on-load tap changer to ensure the voltage quality of the system and users. Currently, transformers with capacities of above 10MVA in developed countries are equipped with OLTCs and the electricity system and users in China are also beginning to adopt more OLTCs. OLTC has become the most critical and at the same time the most expensive component.

OLTC is always compared with off-circuit tap changer. Function of OLTC is generally "to regulate the outlet voltage of the transformer with hot line". Unstable load on the transformer makes the outlet voltage of the transformer decrease or increase. When voltages above the set value range for a long period $(110 \mathrm{kV}, 110-121 \mathrm{kV}, 35 \mathrm{kV}, 35-38.5 \mathrm{kV}, 10 \mathrm{kV}, 10-10.7 \mathrm{kV}, 6 \mathrm{kV}, 6-6.42 \mathrm{kV}$ frequency $50 \pm 0.1 \mathrm{~Hz}$ ), operators need to regulate the number of high-voltage turns (voltage of the 
transformer is proportional to the turns: $\mathrm{u} 1 / \mathrm{u} 2=\mathrm{n} 1 / \mathrm{n} 2$, $\mathrm{u} 2=\mathrm{n} 2 / \mathrm{n} 1 * \mathrm{u} 1$ while $\mathrm{u} 1$ and $\mathrm{n} 2$ are fixed, adjusting $\mathrm{n} 1$ can make $\mathrm{u} 2$ change by $\mathrm{u} 2=\mathrm{k} / \mathrm{n} 1$ ), so as to meet the requirement of outlet voltage.

Tap-change operation starts from the electric motor mechanism that transfers to the bevel gear box through the vertical main shaft, then to the worm gear mechanism on the flange of the switch through the horizontal axis and drives the insulated output shaft by the driving shaft. The rotation of main insulated driving shaft drives the motion of OLTC transmission system. Rotational torque includes two parts, one transferred to the switch energy storage mechanism (rapid mechanism) to store the energy and then driving the switch by energy released by the storage mechanism; the other transferred to the driving shaft on the bottom of the barrel through the switch; due to the connection between the tooth clutch and sheave mechanism of decompose clutch gear selector, rotation of the sheave mechanism drives odd number or even number of contacts of the decompose clutch gear selector to change a position. Thus the odd number or even number of contacts combines with the alternating switches of taps can ensure that tap selector be connected to the desired regulating coil tap without being charged.

\section{Structure}

Switch of the OLTC is air-insulated modular cabinet one that transmits by single resistor and switches rapidly in vacuum. It mainly consists of switch, tap selector, energy storage mechanism, gear box, electrical control and controller, etc.

Switch: Placed in the upper left side of the tap changer, it is driven mainly by the six cams on a camshaft through six vacuum switch tubes. The transmission resistance is placed in the bottom of the vacuum tube according to certain procedure actions.

Tap selector: Placed in the lower left side of the tap changer, it realizes the selection of tap changers by the up and down movement of 12 groups of contacts driven by screw and nuts.

Energy storage mechanism: Placed in the upper right side of the tap changer, it drives switch movement by storing energy in the spring by mechanical mechanism and then release the stored energy in the spring.

Gear box: Installed in the middle of the right side of the tap changer, it mainly changes the motor output speed and transmits the motion to tap selector and storage mechanism.

Electrical control part: Installed on the right bottom of the tap changer, it controls motor running and commutation mainly by AC contacts and relays; it is also equipped with motor protection switch, even stalls and switching protection and so on.

\section{Working Principle}

(1) Before the application of OLTC, oil pillow should be examined. Ensure that there is no oil leakage and that control box is moisture-proof. Make manual operation for a cycle (that is, lifting and releasing for one cycle). Ensure that the position indicator and counter are correct and that the lock of limit position should be reliable, so are the interlocking of manual and electric control.

(2) Gas protection should be equipped in OLTC so that the switch stops under heavy gas and signifies under light gas. It has the same requirement on gas protection with the transformer body. The Buchholz relay of the body is generally referred as "big gas" and Buchholz relay of OLTC is "little gas". Buchholz relay should be installed in a position safe for gas release. After the installation of Buchholz relay on newly applied OLTC, it is necessary for the operator to release the gas timely.

(3) Electric control of the OLTC should be correct; the power supply should be reliable; all terminals should be contacted well. Driving motor should rotate properly and normally; the rated current of fuse should be set 2 to 2.5 times that of the motor.

(4) In the electrical control circuit of the OLTC, the electric operating buttons installed on the control panel and buttons on the OLTC control box of the transformer body should be intact; power 
indicator light and gear indication should be in good condition; electrical locking in the limit position should be reliable.

(5) Current locking device should be set in the electric loop of OLTC as 1.2 times the rated current of the main transformer; current relay return coefficient should be greater than or equal to 0.9. When using the automatic voltage regulator, there must be a counter on the control panel of the main transformer; secondary breaking blocking of voltage transformer in automatic voltage regulator should be correct and reliable.

(6) Newly assembled or repaired OLTC should be operated for trial for a whole cycle by remote electric and present manual operational equipment in the transformer when the transformer is operating with no load. Gear and voltage should be correct; electrical locking of the limit position should be reliable before adjusting the switch into required tap gear to run with a load and strengthening surveillance.

Currently, core barrel is disassembled by opening the bolt connecting the core barrel and jacket and then released down and separated with the jacket by crane hooking the core barrel. This disassembling method demands more operators; in addition, there are also other problems: the complex substation environment, small open space and large number of equipment; especially indoor transformer and crane demolition is inconvenient; strength of the crane is hard to control and can easily damage the OLTC and bring safety hazard to operators. In order to solve the above problems, this paper proposes a core barrel removal tool for OLTC that can reduces the number of operators, is easy to disassemble, reduces the occurrence of OLTC damages and increases the operating safety of disassembles. Technical solution is a core barrel removal tool for OLTC with the following special features: including a crossed horizontal bracket; on the outside of the bracket are four vertical symmetrical holes, through which corresponding screws penetrate; there are upper screw thread and lower screw thread, with the former penetrating through the bracket upwards and connecting with the latter by the screw threads on the upper screw; the bracket is between the upper and lower nuts. The holes are long enough for the adjustment of screw position.

Crossed structure of the bracket makes it load with even force and stay stable; placing the bracket on the top of the jacket of OLTC and fixing screw onto the core barrel of OLTC by lower screw thread make it possible to move screw move downwards against the bracket by turning upper and lower nuts and then separate the core barrel of OLTC slowly from the jacket. The simple structure makes it easy to carry along and reassemble, reducing the number of operators, reducing the occurrence of OLTC damages and improving safety of operations. As shown in Fig. 1

Brief Description

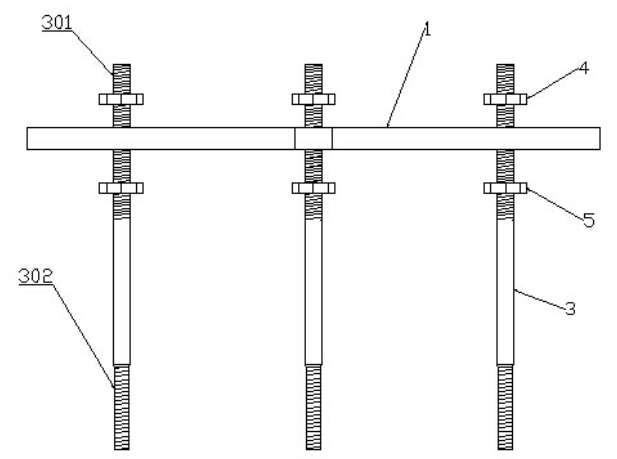

Figure1: Equipment structure

1 - bracket, 2- through holes, 3- screw thread, 301- upper screw thread, 302- lower screw thread, 4- nuts, 5upper nut, 6- jacket, 7- core barrel.

In operation, first remove the bolt connected with bracket 1 between the jacket 6 and core barrel 7 of the OLTC; then place bracket 1 on the top of jacket 6; install screw 3 in the corresponding screw thread hole on core barrel 7 by lower screw thread 302 and make it fixed with core barrel 7; remove other bolts connecting core barrel 7and jacket 6; turning upwards the upper and lower nuts 
4 and 5 to make screw 3 move downwards against bracket 1 , so that finish the operation of slowly separating core barrel 7 of the OLTC from the jacket 6 downwards.

\section{Conclusion}

Two operating screws are equipped with nuts and balance pressing plate with the functions of balance. The balance pressing plate is placed on the hole corresponding with the on-load tap-changer. One end of the two operating screws is inserted into the relevant holes of the on-load tap-changer. The bolts at the two ends are evenly screwed down with adjustable spanner until the dabber of on-load tap-changer descends to the supporting plate, marking the end of the work. The development of this tool will substantially enhance working efficiency and guarantee the overhaul quality. Such design can facilitate the dismounting of on-load tap-changer, reduce manpower and time and enhance economic benefits without damaging the on-load tap-changer because of unstable lifting.

\section{Reference}

[1] Chen Shiqing. On the Condition-based Maintenance of Power Transformer [J]. Transformer.

[2] Lu Jizhi. On the Condition-based Maintenance and Development of Electric Transmission and Transformation Equipment[J ].Yunan Electric Power.

[3] Ma Jie. Carry out Equipment Condition-based Maintenance and Ensure the Safe Operation of Power Grid[J].Sci-Tech Information Development \& Economy.

[4] Ministry of Public Security of the People's Republic of China GB 2006, 50016---2006 Fire proof code of building design [s], China Planning Press, 2006

[5] Ministry of Public Security of the People’s Republic of China GB 50229--- 2006 fire proof design code of thermal power plant and substation[s]. China Planning Press 2006

[6] Ministry of Public Security of the People’s Republic of China GB 50219 --- 95 water spray fire proof design code of water spray[s]. China Planning Press, 1995 